\title{
QUALIDADE DE VIDA E O TRABALHO SOB A ÓTICA DO ENFERMEIRO ${ }^{1}$
}

\author{
CECAGNO, Diana ${ }^{2}$ \\ GALLO, Cláudia M.C. ${ }^{3}$ \\ CECAGNO, Susana ${ }^{4}$ \\ SIQUEIRA, Hedi C. H. ${ }^{5}$
}

Data de encaminhamento: 13 de outubro de 2003.

\footnotetext{
${ }^{1}$ Trabalho encaminhado, sob a forma de resumo, no $55^{\circ}$ Congresso Brasileiro de Enfermagem.

2 Enfermeira. especialista em Enfermagem Médico-Cirurgica. Mestranda em Enfermagem pelo Programa de PósGraduação em Enfermagem da FURG. Bolsista FAPERG. Av. J. K. de Oliveira, 2054, apto. 301 B. Areal- Pelotas/RS CEP 96080-000. E-mail: cecagnod@yahoo.com.br

${ }^{3}$ Enfermeira, especialista em Administração Hospitalar/UNAERP. Mestranda em Enfermagem pelo Programa de PósGraduação em Enfermagem da FURG.

${ }^{4}$ Acadêmica do $7^{\circ}$ semestre do Curso de Enfermagem-UFPEL/RS

${ }^{5}$ Enfermeira e Administradora Hospitalar, professora Adjunta do Departamento de Enfermagem da FURG. Mestre e Doutora em Enfermagem pela UFSC/SC. Membro do Núcleo de Pesquisa NEPES.
} 


\section{QUALIDADE DE VIDA E O TRABALHO SOB A ÓTICA DO ENFERMEIRO}

\section{1- INTRODUÇÃO}

Pensar em qualidade de vida do profissional enfermeiro e suas relações no trabalho faz-nos refletir acerca da importância que este representa, pois, muitas vezes, retrata o estilo de vida adotado por este profissional e sua família.

O termo Qualidade de Vida, conforme consta no instrumento de medida de qualidade de vida -WHOQOL-100 (1998)- foi utilizado pela primeira vez, pelo presidente dos EUA, em 1964, que declarou: "o padrão de vida não pode ser medido através do balanço dos bancos. Eles só podem ser medidos através da Qualidade de Vida que proporcionam as pessoas". Hoje, é possível perceber, através de instrumentos que podem ser utilizados para medir a qualidade de vida, dentre eles, WHOQOL-BREF (1996), WHOQOL-100 (1998), que existe uma ampla preocupação, em nível mundial, no que tange a definição da qualidade de vida e suas relações, dentre elas, o trabalho.

Segundo Souza \& Barroso (1999), o significado de qualidade de vida está ligado à subjetividade das pessoas que associam a este conceito uma dimensão ampliada, a fim de satisfazer as necessidades básicas e aspirações pessoais através de mecanismos de enfrentamento e adaptação às possíveis limitações que possam se apresentar. Concordando com esta idéia, Cárdenas \& Cianciarullo (1999) dizem que qualidade de vida é um conceito marcado pela subjetividade, envolvendo todos os componentes essenciais da condição humana, quer seja físico, psicológico, cultural ou espiritual. Essas autoras citam que "diferentes fatores interferem na qualidade de vida dos indivíduos e, os classificam em indicadores sociais objetivos e subjetivos" (p. 186). Corroboramos com estes conceitos, pois acreditamos na multidimensionalidade que envolve o ser humano e suas relações sócio-ambientais, culturais e pessoais. 
Dentre as relações no que tange qualidade de vida, cremos que o trabalho está relacionado com um melhor bem estar e satisfação pessoal e profissional. Sendo assim, a maneira pela qual o trabalhador percebe e atribui um significado ao trabalho, o modo que está inserido no processo de trabalho e envolvido por ele, terá implicações em sua maneira de viver e ser saudável. Isto significa dizer que, dependendo do tipo de relação do homem com o trabalho, este tem significações diferentes, refletindo em uma melhor ou pior qualidade de vida.

Leopardi (1999) alerta que o trabalho é nuclear na vida de cada indivíduo, e este perde seu caráter de alienação a medida em que o trabalhador busca uma relação embasada na ética, estética, sobrevivência e na liberdade. Neste sentido, constata-se, na enfermagem o empenho de apreender os avanços da ciência da tecnologia por meio do aprimoramento do seu saber e fazer, ou seja, "a busca de qualidade de saúde como qualidade da própria vida(p. 176).

Este estudo surgiu a partir da problematização acerca do conceito de qualidade de vida e suas relações, identificado através de leituras e debates realizados na disciplina de saúde e qualidade de vida do Curso de Mestrado em Enfermagem/Saúde -FURG.

Neste contexto, as autoras investigaram a respeito da percepção de qualidade de vida, relacionada ao trabalho, de enfermeiro(a)s, trabalhador(a)s de um Hospital Escola região Sul do RS.

\section{2- REFERENCIAL TEÓRICO}

Vivemos hoje num mundo globalizado, com uma excessiva mercantilização, não apenas dos objetos, mas também das relações humanas, ameaçando até a própria estrutura humana. Percebe-se que o capital, valor material, em muitos casos está acima do valor do trabalho humano, onde o homem é avaliado apenas por aquilo que produz. A 
forma capitalista de produção dá valor absoluto ao lucro e ao dinheiro deteriorando, assim, os valores que integram a vida em sociedade (Betto, 1998). O mesmo autor diz que a ética do consumo predomina inclusive nas relações sociais.

Alves (1998), reforça a idéia anterior dizendo que as empresas tornaram-se mais complexas na segunda metade do século $X X$ e com isso a gestão de produtos e serviços centraram-se no novo "status" do cliente que passou a fazer novas e maiores exigências. Houve uma diversificação na produção em todos os ramos da economia para atender a ansiedade do consumidor: consumir mais, buscando a possibilidade de melhorar a qualidade de vida, ou seja, viver melhor.

Analisando essa busca desenfreada, vê-se o homem trabalhando muito e vivendo menos. Esses fatos levam a um grande questionamento: onde está, então, a tão sonhada qualidade de vida? Lunardi \& Leopardi (1999) dizem que a organização social do trabalho antecede a análise sobre a questão da qualidade de vida dos trabalhadores, reforçando que, com as características produtivas do capitalismo, os trabalhadores foram submetidos a pressões físicas e psíquicas, levando, assim, a qualidade de vida no trabalho a uma situação inferior ao desejado pela grande maioria dos indivíduos.

Alguns estudos procuram olhar o trabalhador como elemento central do processo de trabalho, percebê-lo em sua singularidade como ser ativo e reflexivo e compreendê-lo numa visão multidimensional. Estes estudos visam resgatar o significado do trabalho como uma experiência saudável, criadora, enriquecedora, contribuindo para a qualidade de vida, conforme abordado por Ramos (1996, p.157), buscando uma dimensão estética, pois:

“... ainda é possível encontrar beleza e poesia, vida e dignidade no trabalho, mesmo quando este trabalho exige se confrontar com limitações concretas, [...] na estetização da existência pela via do trabalho...”. 
Ao analisarmos o agir/trabalhar do enfermeiro enquanto profissional dotado de conhecimentos específicos voltados para o ser humano, complexo por definição, percebemos que a sua subjetividade passa desapercebida, uma vez que está, constantemente, envolvido em inúmeras atividades relacionadas não só quanto a sua competência, mas também a de outros profissionais, ficando sem tempo para refletir criticamente sua prática. Neste sentido, Cezar Vaz (1999, p.58) diz que "os indivíduos se expressam vivos pela significação do trabalho e se incluem no contexto pelo significado coletivo da expressão viva do trabalho".

Diante do exposto, podemos dizer que é necessário fazer uma reflexão crítica do trabalhador em enfermagem e a qualidade de vida deste, visto que inúmeras vezes, o enfermeiro apresenta uma sobrecarga e um excesso na jornada de trabalho afastando-se do convívio social e familiar, contradizendo o que os autores retratam acerca da importância deste convívio e a subjetividade na qualidade de vida. É preciso redimensionar questões éticas e estéticas ao modo de viver do trabalhador da enfermagem a fim de auxiliá-lo não somente a sobreviver, mas a transcender.

\section{3- ASPECTOS METODOLÓGICOS}

O presente trabalho foi realizado num Hospital Escola da região Sul do RS, que tem por finalidade, assistência, ensino e pesquisa. O mesmo é um Hospital Geral, de médio porte e atende exclusivamente pelo Sistema Único de Saúde(SUS), prestando assistência a pacientes de Pelotas e de outras cidades do sul do estado do RS. É contemplado com o Hospital Dia, sendo referência regional, também, pelo serviço de quimioterapia, proporcionando um atendimento especializado nas diversas áreas.

O serviço de enfermagem dessa instituição possui no seu quadro funcional, 32 enfermeiros. No momento da realização desse estudo, 29 enfermeiros estavam atuantes, 
encontrando-se, o restante, em período de licença temporária por interesse pessoal. Todos os que se encontravam atuando foram convidados a participar desse estudo, sendo que 3 optaram por não contribuir.

A coleta de dados foi realizada na primeira quinzena do mês de junho de 2003 através de um questionário aberto (anexo 1). Este foi aplicado no turno de trabalho dos entrevistados e, durante o período em que o respondiam, o entrevistador permaneceu próximo ao entrevistando para garantir agilidade, tanto no retorno do instrumento de pesquisa como para o início da análise dos dados. A média de tempo gasto para responder cada questionário foi de, aproximadamente, 15 minutos.

Para a análise dos dados coletados utilizou-se a técnica de análise de conteúdo proposta por Minayo (2000). Após leitura flutuante, as categorias foram construídas de forma gradual, na medida em que os conteúdos dos dados coletados formam desmembrados em unidades de análise, subcategorias e categorias.

Do total de 29 entrevistados, $11,6 \%$ (3) são do sexo masculino e $88,4 \%$ do sexo feminino (23). A idade deles variou de 24 a 56, sendo a média 34,6 anos. Quanto ao tempo de formado, variou de 3 a 23, com uma média de 12 anos e o período de atuação variou de 10 meses a 24 anos, com média de 11,6 anos. $50 \%$ (13) dos entrevistados trabalham em 2 turnos, 16\% (4) em 3 turnos e 34\% (9) em 1 turno. Em relação ao número de empregos, 19,3\% (5) tem 1 emprego, 73\%(19) tem 2 empregos e 7,7\% (2) tem 3 empregos.

\section{4-ANÁLISE E REFLEXÃO DOS RESULTADOS}

O trabalho, conforme César Vaz (1999, p.66), "se expressa pela produção do indivíduo em estruturas materiais e sociais". Neste sentido, o trabalho está diretamente 
relacionado com as condições de sobrevida e a busca de meios materiais para satisfação das necessidades individuais, assim como a sua inserção no meio social. Através do estudo realizado por Padilha e Souza (1999), ficou demonstrado que o trabalho é identificado como algo significativo e imprescindível na concepção do conceito de qualidade de vida, possibilitando a aquisição de benefícios materiais e realização de desejos. Evidenciamos, nos dados coletados, duas grandes categorias:

- Percepção Pessoal sobre a Qualidade de Vida com as subcategorias: saúde, bem estar físico e mental; questões familiares; trabalho e lazer.

- Importância do Trabalho na Qualidade de Vida com as subcategorias: satisfação e crescimento pessoal e profissional; condição do trabalho; aspecto financeiro.

\section{PERCEPÇÃO PESSOAL SOBRE QUALIDADE DE VIDA}

Quando analisada a questão acerca da definição de qualidade de vida ficou evidenciado a ligação entre saúde, família e ambiente de trabalho, assim como, lazer. Segundo BULLINGER e cols, (1993) "qualidade de vida é um termo geral que inclui uma variedade potencial maior de condições que podem afetar a percepção do indivíduo, seus sentimentos e comportamentos relacionados com o seu funcionamento diário, incluindo, mas não se limitando, a sua condição de saúde”.

Ao relacionar qualidade de vida e saúde Cianciarullo (1998, p.31) enfatiza que:

"O estado de saúde, pressupõem condições dignas de trabalho, renda, de alimentação e nutrição, de educação, de moradia, de saneamento, de transporte e de lazer, assim como o acesso a esses bens e serviços essenciais, e o reconhecimento e salvaguarda dos direitos do indivíduo, como sujeito as ações e serviços de assistência em saúde."

Dos entrevistados, onze pessoas relacionaram sua qualidade de vida com saúde, bem estar físico e mental e assim se expressaram: 
"Pleno Bem- estar físico e mental"(E1). "Para mim significa bem-estar pessoal em todos os aspectos: físico, psíquico e espiritual" (E7). "Para mim qualidade de vida é manter-se sempre com saúde, sem estresse, ter condições de trabalhar e também sócio-econômica que propicie os prazeres de uma vida feliz e em família" (E13).

A relação de qualidade de vida com questões familiares ficou diretamente evidenciada em cinco entrevistas, sendo que várias outras relacionaram indiretamente a família no conceito de qualidade de vida, dizendo:

"Sentir-se satisfeito na vida familiar, no trabalho e se relacionar bem com as pessoas que convive."(E14) "É viver bem, ter trabalho, receber dele, ter condições de oferecer aos seus filhos uma boa educação e ter reservado um tempo para os momentos de laser com a família" (E15) "Ter condições de oferecer a mim e a minha familia moradia, escola, saúde e lazer, e ainda, planejar objetivos e aquisições (bens materiais e outros)" (E22) "Poder atender as nossas necessidades e a família com dignidade e bem-estar social, emocional e financeiro." (E24)

Muitas vezes o trabalhador torna-se distante de seus familiares e de situações da vida diária por ter jornadas longas ou correr entre dois ou três empregos, tornando-se alienado, irritado e estressado. Deste modo, afasta-se do convívio social e familiar, direcionando a maior parte de seu tempo à atividades profissionais, deixando de lado questões subjetivas, pois passa a ver o trabalho em primeiro plano, sem perceber os prejuízos que está acumulando não apenas para si, como também a família.

Quanto a relação do conceito de qualidade de vida com o trabalho e lazer , dezessete entrevistados fizeram referência, expressando-se da seguinte maneira:

"É ter condições de trabalho digno, saúde, lazer, poder acompanhar o desenvolvimento de minhas filhas."(E3). "Ter um trabalho digno, moradia confortável, acesso aos serviços de saúde, relacionamentos estáveis, confiáveis, férias, viagens e lazer."(E6) "Conseguir conciliar trabalho, diversão, vida familiar, saúde, tudo harmoniosamente"(E12) "É poder desfrutar de todos os prazeres que a vida pode proporcionar, bem estar social, emocional, financeiro, no trabalho, familia e amoroso." (E25)

\section{IMPORTÂNCIA DO TRABALHO NA QUALIDADE DE VIDA}


A segunda questão analisada versou sobre a importância que o trabalho tem na qualidade de vida. Pode-se visualizar que o trabalho é percebido como uma ferramenta fundamental, uma vez que dezesseis entrevistados associaram o trabalho com a satisfação e crescimento pessoal e profissional , o que possibilita melhorar sua qualidade de vida, bem como a de sua família, expressando-se assim:

\begin{abstract}
"Satisfação pessoal, tranqüilidade financeira, contribuição social, realização profissional" (E5) "O trabalho é de fundamental importância, pois é além de aspecto de satisfação e realização, é dele que provêm e ganho para o sustento e o provimento das necessidades materiais".(E 7) "Através do trabalho é que a gente pode sentir-se realizada ou mal, refletindo na qualidade de vida"(E 20) "O trabalho proporciona qualidade de vida, na medida que satisfaz psicologicamente quando se gosta daquilo que faz, porém, pode interferir também negativamente." (E23)
\end{abstract}

Padilha e Souza(1999), reforçam a idéia de que, quando as relações de trabalho tornam-se mais respeitosas, quando se prestigia o potencial de cada um, quando ocorre uma relação de confiança no ambiente de trabalho, as possibilidades de sucesso são maiores, e conseqüentemente, a qualidade de vida. Corroboramos com a assertiva das autoras, pois a satisfação pessoal e profissional está parcialmente pautada com a significação que cada indivíduo atribui a atividade que exerce.

A grande parte dos indivíduos, seres humanos insatisfeitos, esgotam-se no trabalho e não encontram tempo para restaurarem forças internas (LUNARDI e LEOPARDI, 1999).

A capacidade de cultivar amizades e manter relacionamentos, as habilidades interpessoais para viver e trabalhar em grupo precisam ser desenvolvidas para criar um convívio harmonioso e sadio (MOSCOVICI, 2001). Acreditamos que o ambiente de trabalho represente parcela significante no aspecto motivador, pois, segundo essa autora, "faz diferença trabalhar num ambiente agradável, bem localizado, confortável e que possibilite personalização” (p.139). Cinco entrevistados, ao relacionar condição de trabalho e qualidade de vida, relataram: 
“... o ambiente de trabalho está diretamente relacionado à qualidade de vida no que diz respeito ao relacionamento com colegas e disposição para trabalho."(E2)"O trabalho está diretamente relacionado coma qualidade de vida, pois se tenho um bom emprego posso ter uma vida melhor." (E 8) "O trabalho é a segunda casa, é muito importante a condição de trabalho que temos para termos uma boa qualidade de vida, estamos diariamente convivendo com as mesmas pessoas e no mesmo ambiente, se não estivermos bem neste ambiente não estaremos bem também no ambiente familiar e vice-versa." (E12).

Defendemos a idéia de que um investimento em melhoria nas condições do ambiente de trabalho envolve não só os aspectos físicos do local de trabalho, mas também a humanização deste ambiente, isto é, a valorização do profissional e reconhecimento do seu "eu".

Observamos, através dos relatos de onze dos entrevistados, que o aspecto financeiro está atrelado aos recursos disponíveis para a manutenção e satisfação das necessidades básicas do ser humano, aqui, o enfermeiro, bem como proporcionar satisfação pessoal e profissional, pois com salários justos é possível melhorar a condição econômica, assim expressada:

“O trabalho me traz os recursos monetários necessários para o equilíbrio desta qualidade de vida. Também o trabalho é minha terapia”(E3). " "Ele vai me proporcionar as condições de melhoria na condição econômica, bem como satisfação pessoal de exercer a profissão que gosto" (E13). "Hoje se você não trabalho e se não nasceu em berço de ouro não tem como ter qualidade de vida, pois qualidade custa dinheiro"(E15). "O trabalho para mim é básico, pois além de fazer o que eu gosto e onde gosto, garante o ganho financeiro necessário para suprir minhas necessidades"(E19).

\section{5- CONSIDERAÇÕES FINAIS}


O conceito de qualidade de vida dos enfermeiros entrevistados nesta pesquisa está relacionado com o bem estar e saúde do ser humano e sua família, bem como com questões ampliadas envolvendo educação, lazer, moradia e trabalho.

Ao concluirmos este estudo constatamos que o trabalho tem relevante significado na qualidade de vida do profissional enfermeiro. Os dados coletados evidenciaram que o trabalho direciona o estilo de vida adotado por este profissional e sua família. O ambiente de trabalho e o próprio trabalho tem importância singular para estes profissionais, representa um marco operador na qualidade de vida, uma vez que diferentes valores foram atribuídos a ele, muito embora todos o relacionaram com uma possibilidade de melhor condição de vida e ser saudável.

Em busca desta "melhor qualidade de vida", 66\% dos entrevistados trabalham em dois ou mais turnos e $80,7 \%$ tem mais do que um emprego. Isso nos leva a questionar: Onde está a tão sonhada qualidade de vida? Estando a maior parte do dia trabalhando, este profissional tem tempo para atender os critérios que ele mesmo estipula para ter qualidade de vida?

Ressaltamos que este estudo proporcionou, aos entrevistados, conforme relatado verbalmente no momento da coleta de dados, uma reflexão sobre as questões abordadas, pois a maioria disse: "não tinha parado para pensar nisso e como é difícil responder isso!"

Diante do exposto, podemos dizer que é necessário fazer uma reflexão crítica sobre a qualidade de vida do trabalhador de enfermagem, visto que inúmeras vezes, o enfermeiro apresenta uma sobrecarga e excesso na jornada de trabalho afastando-se do convívio social e familiar, contradizendo o que os autores e os próprios entrevistados retratam acerca da importância deste convívio e a subjetividade na qualidade de vida.

\section{6- LITERATURA EXPLORADA}


ALVES, M. A Gerência do Cuidado de Enfermagem frente aos novos modelos de gestão. In: Anais do $50^{\circ}$ Congresso Brasileiro de Enfermagem-Mesas Redondas. pg. 153-158. Salvador, 1998.

BETTO, F. Ética, Exercício Profissional, Exercício da Cidadania. In: Anais do $\mathbf{5 0}^{\circ}$ Congresso Brasileiro de Enfermagem-Conferências_pg. 49-56. Salvador, 1998.

BULLINGER e cols. Instrumentos de Medida de Qualidade de Vida.Texto disponível no site: http:// www. EEAC-network.org. Acessado em 03/04/03.

CEZAR VAZ, M. R. C.Trabalho em Saúde: expressão viva da vida social. In: O Processo de Trabalho em Saúde: organização e subjetividade. Maria Tereza Leopardi (org.). Florianópolis:Papa-Livros, v.1, p. 47-67,1999.

CIANCIARULLO, T. et al. A hemodiálise em questão: opção pela qualidade assistencial. São Paulo: Ícone, 1998.

LEOPARDI, M.T. a Vida do Trabalhador como centralidade no Trabalho. IN: O Processo de Trabalho em Saúde: organização e subjetividade. Maria Tereza Leopardi (org.). Florianópolis: Papa-Livros, v.1, p. 49-55,1999.

LUNARDI FILHO W. D.; LEOPARDI, M. T. O trabalho da enfermagem: sua inserção na estrutura do trabalho geral. Rio Grande,1999. 84p.

MINAYO, M. C. S. Pesquisa Social. 6. ed. Rio de Janeiro: Vozes, 2000.

MOSCOVICI, F. A organização por traz do espelho: reflexos e reflexões. Rio de Janeiro: José Olympio, 2001.

PADILHA, M. I. C. de S.; SOUZA, L. N. A. de. Qualidade de vida - Reflexão de Enfermeiras. Texto \& Contexto Enfermagem, Florianópolis, SC, v. 8, n. 3, p. 11-26, set.dez., 1999.

RAMOS, F.R.S. Obra e Manifesto: O desafio estético do trabalhador de saúde.

Pelotas: ed. Universitária/UFPel,1996. 
SOUZA, L.J.E.; BARROSO, M.G.T. Qualidade de vida na criança acidentada. . Texto \& Contexto Enfermagem, Florianópolis, SC, v. 8, n. 3, p. 308-317, set.-dez., 1999.

WOHQOL-100 1998 - Instrumentos de Medida de Qualidade de Vida/ desenvolvimento do WHOQOL-100. Texto disponível no site: http:// www. EEACnetwork.org. acessado em 03/04/03.

WHOQOL-BREF - Introduction, Administration, Scoring and Generic Version of the Assessment. Fiel Trial Version. Programme on Mental Health. World Health Organization. Geneva, December, 1996. 